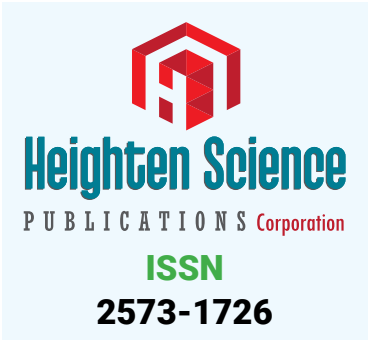

*Address for Correspondence: Antonín Cuc, Prague CZ, expert in Cybernetics and Health and Safety Medical Devices OECD, Czech Republic, Email: betruea@gmail.com

Submitted: 25 June 2018

Approved: 16 July 2018

Published: 17 July 2018

Copyright: @ 2018 Cuc A. This is an open access article distributed under the Creative Commons Attribution License, which permits unrestricted use, distribution, and reproduction in any medium, provided the original work is properly cited
Prospective

\section{The Courage to implement Samplings to evaluation efficiency Medical Clinics OECD}

\author{
Antonín Cuc* \\ Prague CZ, expert in Cybernetics and Health and Safety Medical Devices OECD, Czech Republic
}

\section{Annotation}

We are able to test with statistic method Based Evidence Medicine the new Medicaments on common World Market or the new Medical Devices - Orthopaedic implants. Of course, with usage the same principles we could Tests similar ways the explicit efficiency, legalities and Technical Requirements Laws by Medical processing for implanting by standard Health care in Orthopaedic Clinics in network OECD.

I have been opened the new Epoche, for examples to comparison of workflow and efficiency in produce Health care in Orthopaedic Clinic OECD with authorised my Utility model 21532 CZ 2010 The Equipment for Search and Retrieval sufficient information to Mass reuse for repeated similar strategic decision making with risks and computer support.

The continual Mass produce Health care services Patients OECD in Medical Clinics could be analysed regularly with double parallely degrese levels of realised random Samplings. The first random choice of selection could be organised by the views of the randomized choice specific medical Clinics, for example defined as Orthopady Clinic in frame network OECD. And the basal first level could be defined as the elementary statistic Unit - the hospitalised orthopaedic Patient in defined finished year for description, for example in year 2016, which were hospitalised in some Orthopaedic Clinic at least the 3 days or more days.

There are no problem to define statistic Population N for year 2016 of orthopaedic Patients, recommending proportional dimension $\mathrm{n}$, for example as $3 \%$ from the origin statistic population $\mathrm{N}$. The main aims of analyses should be resulting the multilateral views on the medical legality and technical quality, economic Costs and Health efficiency of used standard Medical processing by the Diagnostics and Treatments and prevency risks of orthopaedic Patients in statistic comparison the Orthopady Clinics in countries OECD. We could take to statistic collections from, the Secondary Health Patient Datas "derived by specific algorithm - from the origin living full databases Electronic Health Documentation of all hospitalised Patients in Clinics. It could be clever fulfilling enough - with specific next statistic views, with next additional small „Unique Primary Terain Samplings" with about random in Dimension about 200 statistical Units, for example with primary medical forensic testing namely - the mortalities and heavy injuring of orthopaedic Patients in duration 10 months after surgeries realised in year 2016, or with additional statistic analyses - long being post operational locomotion and mental abilities in comparison Orthopaedic a few US Orthopaedic Clinic, and Samplings oriented on views on rest quality „Well Being“ of lives some living orthopaedic Patients with Surgeon Total Arthroplasty in 2016 - for example after probable 3 years from the orthopaedic standard primary surgeries with usage always full Anesthesy for all 
types Total Arthroplasty: hips, Knees, Spinal elements, so as the all causalities for inforced preliminary reoperational surgeries under limits 10 years from the primary arthroplasty surgeries. The Results of such scientist independent Samplings will be changed revolutionaire innovations of all medical praxes in workflow and managing styles in all Orthopady Clinics in network OECD!

Such statistician combined multilateral analyses - it should be organised with evaluation with competent experts in Orthopady, with experts in Forensic Orthopady, expert as Statisticians including Cybernetics, namely from participants on today's archiving databases EHRs, Programmers IT for EHRs in Orthopady Clinics, of course so as with Technicians experienced from the field Development of new Medical Devices and similar Clinic testing in field Orthopaedic implants. We could cooperating with participants from judicial experts for Patient Human Rights, with experts in human Radiology, with experts in Health and Safety usage products with "CE“ marking by users, with experts for controlling mandstory prevency of known Patient risks by Protocols "CE“ of implants - products "CE“, etc. The well organised Team of Experts for such multilateral Statistic Tasks, should be well educated and with preliminary guarances perfect run in!

The first Task for understanding such team, it should be well evaluated my case why I am needless illegal heavy orthopaedic injured with my casual continual growing next orthopaedic and leukemic individual complications and with continual biostatistics growing Patient risks to preliminary inforced dying for more probable repeated fatal fall with breaking the femoral bone - all with false coded individual Health care as in limits of working medical staff, "Lege artis CZ", so as in the false derived Judgement No 36 C 181/2009-221 since September 24, 2012 - namely after many technical and medical fatal illegal procedural medical mistakes in illegal preparing individual Clinic Plan of standard surgeon classic Total Arthroplasty in Hips, with next illegal processing on the surgeon Hall by implantation set THA contrary Technician requirements of Laws and contrary Product invoids, with next illegal post operational Health care for me with repeated false interpretation preliminary and post operational RTG Images Hips, etc.

There are no Chance to organise the continual rational yearly Samplings of the Produce Health care in a like hood Orthopaedic Clinic, when the Orthopads, Radiologists, Forensic Physicians, expert in Health and Safety and jourists are not able to build collective consistent technical, medical legal validated results with justified Criminal evidence only. It is heavy collective discussions without rational results - nor on the history and results for the first happened Entity in choice, I am - ONE Patient CZ with individual history of needless implanting sum 3 implanting sets THA Bicontact S, nocemented - when there are preliminary perfect my Patient Hypothese about right medical Diagnose: "Necrosis of femoral Head", allways in first stadium - and that for with encyclopedic orthopaedic recommeding there are should taken "Non-surgeon treatments in time", as I am protocolling as orthopaedic Patient CZ in private documentation EHRs - but without a likehood medical serious Interests of my responsible Orthopads, Neurologists, Traumatologs, Radiologs! I was accept as the working material for Health care only - without Freedom to dialogues with Physicians!

Just I am needless heavy orthopaedic injuring and casual preliminary dying Patient CZ after ignoring the Crash "Fausse route Stem" - on Mass of repeated fatal illegal orthopaedic processing implanting partial mistakes, but despite it was false declared official as a judicial case always - with medical regards to always working medical staff CZ „Lege Artis CZ" with acceptance many illegalities in the One orthopaedic Unit in Unique Entity in the beginning the creature Sample (Figure 1).

There are not important, number of false repeated Standpoints of judicial orthopaedic experts, but: What there are explicit multilateral criminal sufficient scientic 
STARS - The description with minimum sufficient statistical information
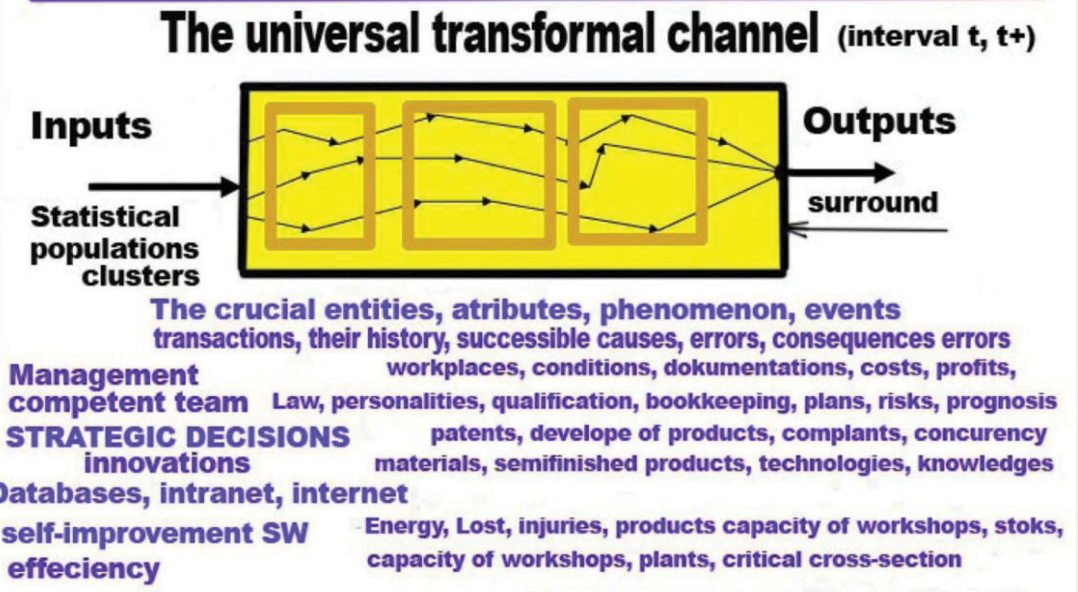

Figure 1:

evidences to define objective TRUTH about illegal implanting, despite my OponentsPhysicians wisdom constantly inforced me judicial and medical needless Execution and orthopaedic casual Death: Out of my civic Human Rights - to live, to participate on the justified Court trials processing only, with scientist exact Criminal evidences only, with Constitutional guarancy my private Human Rights CZ to place by the Court trials the Criminal evidences as a respectable Plaintiff by the independent justified judicial Process CZ with validated Court Medical Message only - it was accepted by the Judge false - without a likehood correcture of criminal mistakes in Biomechanics, in Geometry $3 \mathrm{D}$, in Radiology traceing the criminal medical processing acts, out of Criminal Anthropology evidences! This experts are my cooperative Murders, no participants to find mistakes and Trueth. Don't repeat the similar medical fatal illegal processing mistakes in Orthopady Clinics OECD! With lack of medical Ethics and without well motivation to innovation todays medical workflow with todays repeated Mass false medical illegal habits - you could forget a likehood next Statistician evidences, when you are "always Perfect Phyisicans" - without a likehood legal responsibilities to your orthopaedic Patients, because you are namely probable Gods.

There will be probable derived many extremal many critical revolutionaire exact views and results on today's acceptance the false medical processing in orthopaedic Clinic as false illegal workflow contrary results in Clinic Tests of implants - Out of declared legality, Out of guarancy Technical Quality of implanting, Out of guarancy the hopening to human Rights to live without inforced shorten lives of Patients CZ - after the legal medical processing only $[1,2]$.

Of course -we should be able to difference primary in the the Clusters with Legal Units OR paralelly Clusters with illegal medical processing, probable with supports of computer support. Have you courage? When we could evaluating a likehood Medical processing as „Lege artis OECD“, there are logical a legal conditions for the sequential partial medical activities - there never could be in content nor the ONE partial illegal medical activites - out of Technician Requirements of implanting Laws OR out of sequential right ordering, legal timing, without a likehood absency some important partial medical act, becsause the Binary Logics derives by conjunction of likehood sequential phenomenons allways by evaluation some superposition only FALSE - in the likehood mixage evaluations Truth, False (Figure 2).

All individual Medical processing is definitely FALSE and Illegal for ever - when there are contenting at least the ONE partial medical or technical illegal mistakes contrary implanting Directive 93/42/EEC Medical Devices. Namely by the Directive 
SARS Statistical Retrieval and Search information for decision making

Statistické vyhledání a znovuužití informace k rozhodování

(C) Ing. Antonín Cuc, Praha 1976

Chráněno jako Užitný průmyslový vzor ČR od roku 2010

\section{Consequents discovery S_T_A_R_S}

as a new cybernetic model to concatenation of sequential decision making

Every innovation could be evaluated with high probability as a statistical multicriterial hypothesis about significant differences in estimates of important statistical parameters of existing and future in a Transformal Channel, with regards to a reasonable actual level of statistical reliability and accuracy of strategic decision-making of purpose and destination of the transformation behavior of the channel with recognizing its internal and external risks and considering its likely long-term existence in interaction with significant surroundings.

It could be used to take priorities in choice of variants innovations.

All transformation processes in managing so as in managed processing should be continuously provided subject to continuous minimize summ increases of entropy.

Figure 2:

93/42/EEC Medical Devices there are illegal each implanting processing - when there were absence of mandatory individual Clinic Plan of Surgeon THA. There are all medical implanting processing illegal and false - when there are for example: finished assembling of Product - set THA in Patient Body, out of biomechanical perfect funcionalities on surgeon Hall and out of mechanical tolerances by the Producer of product, or when there are used the illegal anchoring the orthopaedic component out of centric functional coaxialities between Femoral bone and used the Stem - contrary firm installing radiologic Masks of used set THA, etc., etc.

None of those principles where respected in my destruction of femoral cavity with false placement of the Stem by hitting in false angle 13, 68 grads, punctuare through the femoral cavity, when the Orthopad began working illegal - without preliminary individual Clinic Plan! None such criminal traceing of criminal implanting on surgeon hall "Fausse route stem" could be realised with hypothetic false Imagine happened postoperational Patient fallen - when the origin placement of the Stem was "probable“ acceptable with prescribed accuracy by the Producer invoid. Such false Medical Hypothese was placed in the Court medical Message No. 36 C 181/2009-123 since March 27, 2012 by the Regional Court Prague, contrary Criminal traceing [3,4].

But the Judge JU Dr. Vojtěch Cepl prefered false Medical Court Message contrary all my Patient protests - I sent him the criminal exact biomechanical arguments to his hands by the letter since July 17, 2012. The Judge, so as my Culprits - Physicians and orthopaedic Court Experts ignored my criminal evidences - They are asking in Collective decision - my judicial Defeat and my criminal Death, without a like hood medical and judicial Ethics.

My repeated requests for a new consideration of my complaint in the next Criminal Court proceeding were with absurd arguments both - from the Criminal Police of the Czech Republic and also from the State Prosecutor's Offices of the Czech Republic each time they were rejected. That is why I am waiting for an finished a unfair civil Court - the unnecessary and medically criminally forced my Death of orthopaedic Patient CZ, it be said in the contextual usual observance of the rules and medical habits in force in the Czech Republic - LEGE ARTIS CZ!? contrary Lege artis OECD (Figure 3).

\section{Results}

There were only 1 Unit in the Sample in Cluster with illegal implantation THA - it were enough to detect the absurd Compact medical repeated stupidities many Orthopads, 


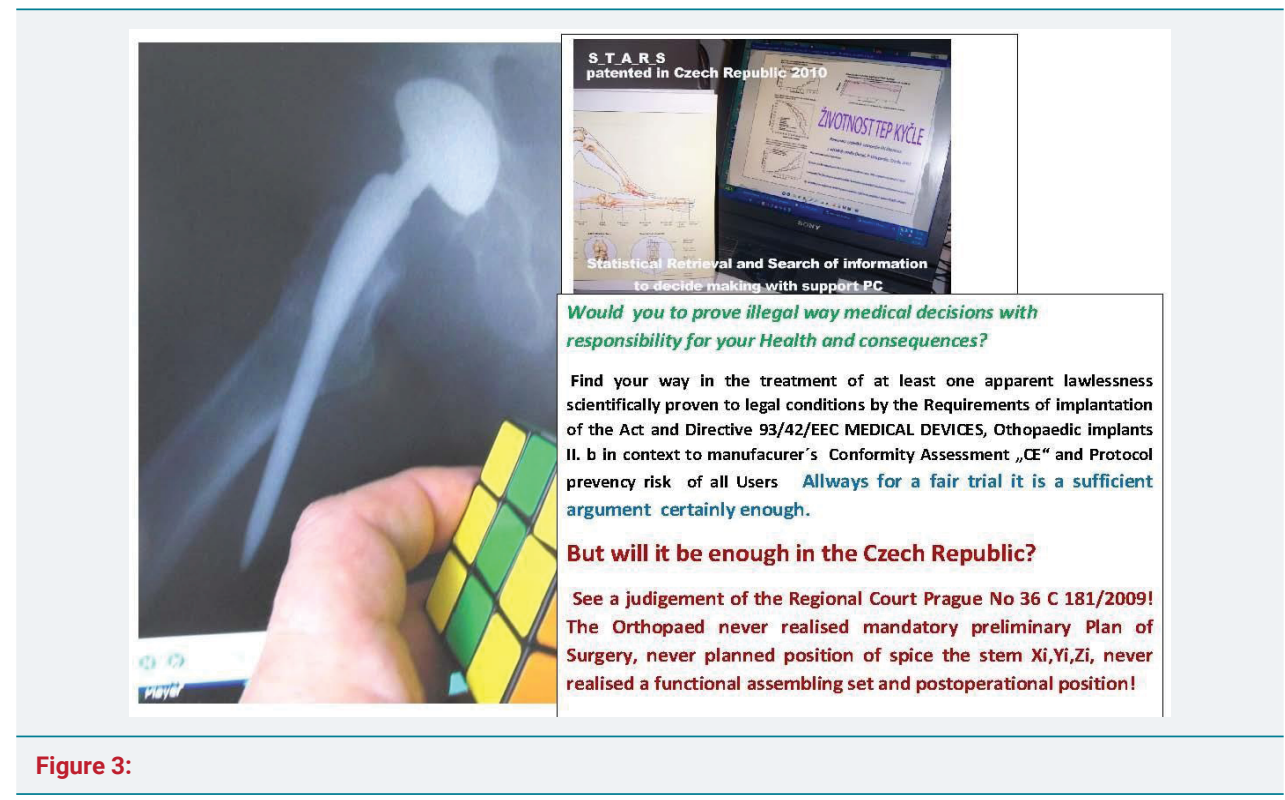

Radiologists, Forensic doctors and Criminal cooperating Team Police CZ with medical staff of orthopaedic Clinic - The Hospital Mladá Boleslav CZ and medical staff are working against my Patient Rights to legal Health care CZ and against my civic Human Rights CZ to live, to be Healthy, to spent the Rest my life without illegal inforced me Shorten my Life radically about a few years - with covering all illegal medical mistakes in virtual Legalities of false semantic expression „Lege Artis CZ, similar ways as the next parallely 40 thousands of Patients CZ yearly - which there are heavy needless injured with casual inforced me preliminary Death after illegal medical processing.

Similar ways are in the Czech Republic yearly needless heavy crippled and casual with inforced preliminary Death about many years. It is full actual for about 40 thousands of Patients yearly. I have no Chance to my judicial Defence by private Constitutional Claim CZ, when it costs the beginning Court fees 40 thousands CZK and next parallely inforced Advocate fees 40 thousands CZK. The Ombudsman CZ so as the Chairman of Constitutional Court CZ were informed a few years ago, but for them these certificated illegalities are full acceptable, including agreements the Departments Criminal Police CZ and for State Penalty Offices CZ too.

The Contextual and Used Literature

1. Antonín Cuc. Utility model 21532 Czech Republic, 2010 the Equipment for Search and Retrieval of sufficient information to Mass reuse for similar repeated strategic decision making with risk and computer support.

2. Antonín Cuc. The Health Patient orthopaedic documents from false implanting THA since November 13, 2007-Complaint to judicial civic Court trial of the Regional Court Prague, No. 36 C 181/2009 since November 2009, with the Medical Court Message from the Central Army Hospital Prague CZ No. 36 C 181/2009-123 since March 27, 2012.

3. The Letter of Plaintiff Ing. Antonín Cuc to Judge JUDr. Vojtěch Cepl and paralelly to all other Participants of Court Trial 36 C 181/2009, with criminal evidences of illegal implanting processing set THA in the Surgeon orthopaedic implanting set THA, Bicontact S, Noncemented from the firm B. Braun, Germany since delivering letter in July 17, 2012, reprint is published in my private Linkdedin Profile to all members of scientic international nets.

4. Antonín Cuc. On a Criminal Trace of Crippling and Often Even Lethal False Diagnosis: Lege Artis CZ. Orthop Sport Med Op Acc J. 2018; 1. 